\title{
Mechanism of the hyperketonaemic effect of prolonged exercise in insulin-deprived Type 1 (insulin-dependent) diabetic patients
}

\author{
F. Féry ${ }^{1}$, V.de Maertelaer ${ }^{2}$ and E.O. Balasse ${ }^{1}$ \\ ${ }^{1}$ Laboratory of Experimental Medicine and \\ ${ }^{2}$ Statistical Unit of Institute of Interdisciplinary Research, University of Brussels, Brussels, Belgium
}

Summary. The effects of moderate exercise of 2-h duration on the concentration and turnover rate of total ketone bodies were assessed in 7 acutely insulin-deprived Type 1 (insulindependent) diabetic patients with an isotope tracer technique using a constant infusion of ${ }^{14} \mathrm{C}-\beta$-hydroxybutyrate. These results were compared to those obtained in 13 normal control subjects in whom a similar range of hyperketonaemia $(\sim 1-6 \mathrm{mmol} / \mathrm{l})$ was induced by fasting. In all subjects, the concentration and the rate of production of ketone bodies followed a biphasic pattern with an initial fall lasting for about $20 \mathrm{~min}$ followed by a secondary rise. When integrated over the entire working period, the exercise-induced changes in ketone turnover were markedly dependent on the initial ketone body concentrations in both groups: at low ketonaemia $(\sim 1 \mathrm{mmol} / \mathrm{l})$, exercise increased the rate of production and disposal of ketones. These effects were progressively attenuated as basal ketonaemia rose and were reversed to an inhibitory action in markedly ketotic subjects $(>4 \mathrm{mmol} / \mathrm{l})$. Despite the finding that, at high ketosis, exercise inhibited ketogenesis to a similar degree in control subjects and diabetic patients, the changes in concentration recorded at the end of exercise were different in the 2 groups: ketonaemia was reduced in fasted control subjects and increased in the diabetic patients. These data suggest that, contrary to a widely accepted opinion, the hyperketonaemic effect of prolonged exercise in ketotic diabetic patients does not result from an exaggerated stimulation of ketogenesis, but from some defect in their removal capacities for ketones, possibly related to insulinopenia.

Key words: Exercise, diabetes, diabetic ketosis, ketone bodies, turnover of ketone bodies, acetoacetate, $\beta$-hydroxybutyrate, non-esterified fatty acids.
The metabolic effects of exercise in Type 1 (insulin-dependent) diabetic patients depend on a variety of factors, among which the patient's state of glycaemic control and the time elapsed since the last insulin injection play essential roles. When exercise is performed by a patient under good metabolic control shortly after a subcutaneous insulin injection, there is a subnormal rise in fat-derived substrates and a fall in blood glucose which can lead to severe hypoglycaemia [1]. On the other hand, in ketotic hyperglycaemic insulin-deprived diabetic patients exercise provokes a further elevation in glucose and ketone body levels [2]. The mechanisms responsible for the hyperglycaemic action of work observed under these conditions have been carefully investigated in human and animal studies $[1,3,4]$, whereas the data concerning the changes in ketone body (KB) transport are much more scarce. Furthermore, the response of ketotic diabetic patients has been compared to that of non-ketotic normal control subjects which is, in our view, an inappropriate comparison
[5-7]. Indeed, we have recently shown [8] that, in fasted subjects, the response of $\mathrm{KB}$ kinetics to exercise is highly dependent on the initial value of ketonaemia.

The present study was consequently undertaken to analyze the effects of exercise on KB transport in insulin-deprived Type 1 diabetic patients, and to compare them with those obtained previously [8] in normal subjects with a similar degree of ketosis induced by fasting.

\section{Subjects and methods}

\section{Subjects and study design}

Seven Type 1 diabetic patients whose clinical and laboratory characteristics are recorded in Table 1 volunteered for the study. None of the patients had clinical signs of neuropathy or arteriopathy. The purpose, nature and potential risks of all the procedures used were carefully explained to the patients before obtaining their written con- 
sent to participate. The experimental protocol was approved by the institutional Ethics Committee.

All patients received their last subcutaneous injection of intermediate-acting insulin $49-50 \mathrm{~h}$ before the study; only three of the patients $(2,4,7)$ had a last subcutaneous injection of regular insulin $33-39 \mathrm{~h}$ before the study. The subjects were admitted to the hospital on the day preceding the experiment, a few hours after breakfast. On their arrival, an intravenous insulin infusion was immediately set up in order to restore plasma glucose to normal. During the rest of the day the patients received their usual meals, and the insulin infusion rate was adjusted hourly to maintain near euglycaemia. The intravenous insulin infusion was discontinued during the night between 02.00 and 05.00 hours. From this time onwards, ketonuria and glycosuria were determined on each micturation. The study was begun when a significant ketonaemia (Acetest ++ to +++ ) appeared. At that time a constant infusion of potassium $\left[3-{ }^{14} \mathrm{C}\right]-\mathrm{D}-\beta$-hydroxybutyrate (New England Nuclear, Boston, Mass, USA) diluted in saline was begun and delivered at the rate of $0.72 \pm 0.02 \mu \mathrm{Ci} / \mathrm{min}$ through a small catheter inserted in an antecubital vein. The infusion, which lasted for $210 \mathrm{~min}$, was preceeded by a priming dose representing 76 times the amount infused per min. After $90 \mathrm{~min}$ rest, the patients were exercised on a treadmill at a constant intensity representing $49-55 \%$ of their maximal aerobic capacity [9]. Venous blood samples were obtained during the last $30 \mathrm{~min}$ of rest, the $120 \mathrm{~min}$ of exercise and a 60-min postexercise period through an indwelling catheter located in an antecubital vein of the arm opposite to that used for the tracer infusion. The schedule of blood sampling is shown in Figure 1. The tracer infusion was discontinued at the end of exercise so that turnover data were not available for the postexercise recovery period. The subjects voided before the start of the study, and urine was collected at the end of the experiment.

This protocol is identical to that used in a previous study [8] in which we analyzed the response to exercise of 21 normal subjects presenting fasting ketosis ranging between 0.09 and $6.16 \mathrm{mmol} / \mathrm{I}$. The 13 subjects of this group whose total KB levels exceeded $0.6 \mathrm{mmol} / 1$ have been selected to serve as controls for the present work on ketotic diabetic patients, and their basal metabolic characteristics are displayed in Table 1.

\section{Methods}

Acetoacetate, $\beta$-hydroxybutyrate, glycerol and glucose (glucose-oxidase method) concentrations were determined on a neutralized perchloric acid filtrate of plasma using standard enzymic methods [10]. Non-esterified fatty acids (NEFA) [11], insulin (Phadebas insulin test, Uppsala, Sweden), cortisol (Gamma-coat cortisol radioimmunoassay kit, Travenol, Cambridge, Mass, USA) and growth hormone [12] were measured on heparinized plasma, while plasma for glucagon determination [13] was collected on sodium EDTA containing aprotinin. ${ }^{14} \mathrm{C}$-acetoacetate and ${ }^{14} \mathrm{C}$ - $\beta$-hydroxybutyrate concentrations were assayed on the perchloric filtrates according to the slightly modified method of Mayes and Felts $[14,15]$. The rate of appearance ( $\mathrm{Ra}$ ) and the total rate of disposal of total $\mathrm{KB}$ were calculated in the nonsteady state according to be equations developed by Steele [15] using the combined specific activities of acetoacetate and $\beta$-hydroxybutyrate. The ratio of these specific activities was not significantly different from unity in either group at rest or at exercise, indicating that the two compounds were in isotopic equilibrium. It was assumed that the "operational" volume of distribution represents $10 \%$ of body weight [17]. The methodological problems inherent in this calculation procedure have been widely discussed in several of our previous publications $[8,17,18]$. The urinary elimination of $\mathrm{KB}$ was subtracted from the total rate of disposal to yield the metabolic disposal rate (Rd). Turnover values have been normalized to a body surface of $1.73 \mathrm{~m}^{2}$.

\section{Statistical analysis}

Results are given as means \pm SEM. Within each group, the statistical significance of the changes from mean basal value induced by exercise was evaluated at each time-point by paired Student's t-tests. Comparison between groups of the changes from mean basal value was made for the following periods: $0-30 \mathrm{~min}, 30-90 \mathrm{~min}$, end of exercise and postexercise period ( $0-60 \mathrm{~min})$, except for $\mathrm{Ra}$ and $\mathrm{Rd}$, for which the comparison was limited to the $0-30 \mathrm{~min}$ and $30-90 \mathrm{~min}$ periods, data for later periods not being available in all subjects. For this purpose, each set of data was submitted to a two-way analysis of

Table 1. Characteristics of Type 1 diabetic patients and control subjects

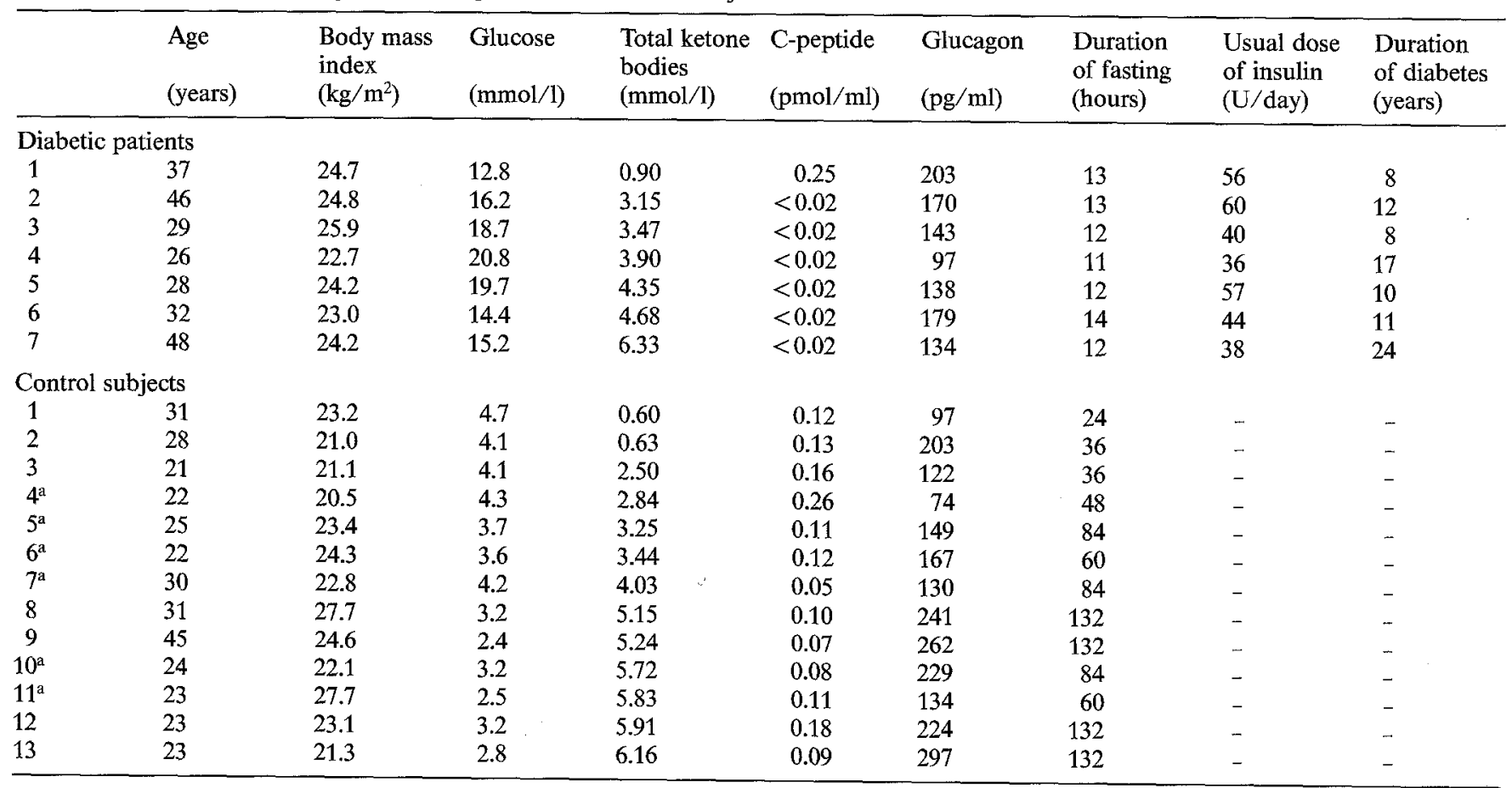

All subjects were male except diabetic patient 3 . The control subjects were taken from a previous study [8]

${ }^{a}$ Subjects selected on the basis of their ketonaemia to serve as control subjects for diabetic patients 2-7 in Figures 1 and 2 
variance. The model considered includes a fixed grouping factor at two levels (control subjects and diabetic patients), a fixed within factor ("time") and their interaction. Computations have been performed with the use of the BMPD Statistical Software, BMDP2V program [19]. Linear regression and covariance analysis for evaluating differences between slopes of regression lines have been performed according to standard statistical methods [20]. A $p$ value of $<0.05$ was considered statistically significant.

\section{Results}

\section{Resting state}

Figure 1 represents the mean substrate and hormone concentrations obtained at rest, during and after exercise for the 6 most ketotic diabetic patients $(2-7)$ compared to 6 normal fasted subjects. The latter were selected from those presented in Table 1 so that both their individual and their mean total KB level would match as closely as possible those of the diabetic patients.

In the resting state, the mean total $\mathrm{KB}$ concentration (and range) was $4.31(3.15-6.33) \mathrm{mmol} / 1$ for the diabetic patients and $4.18(2.84-5.83) \mathrm{mmol} / 1$ for the control subjects. The average resting levels of NEFA, glycerol, lactate, glucagon, growth hormone and cortisol were also quite comparable in both groups (Fig.1). The turnover rate of total $\mathrm{KB}$ (not shown in Fig. 1) was $1.61(1.04-2.10) \mathrm{mmol} / \mathrm{min}$ in the diabetic patients versus $1.36(1.11-1.97) \mathrm{mmol} / \mathrm{min}$ in the normal subjects. For none of the above-mentioned parameters was there any statistically significant difference between the two groups. The average plasma glucose level was $17.6(14.4-20.8) \mathrm{mmol} / \mathrm{l}$ in the diabetic patients, and they had unmeasurable plasma levels of C-peptide.

\section{Exercise period}

Substrate and hormone concentrations. The exercise test was well tolerated until the end by the diabetic patients except in subjects 5 and 7 , in whom work was interruped after $90 \mathrm{~min}$ owing to slight nausea and fatigue. These symptoms disappeared on cessation of work so that the experiment could be pursued normally during the postexercise period. In Figure 1, the last exercise value represents the mean of those obtained at $120 \mathrm{~min}$ in four patients and at $90 \mathrm{~min}$ in two patients.

In diabetic patients (Fig.1), exercise induced a slow rise in acetoacetate concentration which persisted during the post-exercise period. The increments above mean basal value recorded at the end of exercise and after $1 \mathrm{~h}$ of postexercise recovery amounted respectively to $+0.56 \pm 0.07 \mathrm{mmol} / 1 \quad(p<0.001)$ and $+0.77 \pm$ $0.05 \mathrm{mmol} / 1(p<0.001)$. In contrast, $\beta$-hydroxybutyrate concentration followed a biphasic pattern with an initial fall averaging $-0.57 \pm 0.16 \mathrm{mmol} / 1(p<0.02)$ at $20 \mathrm{~min}$ followed by a secondary rise, the average increment above mean basal level amounting to $+0.61 \pm$

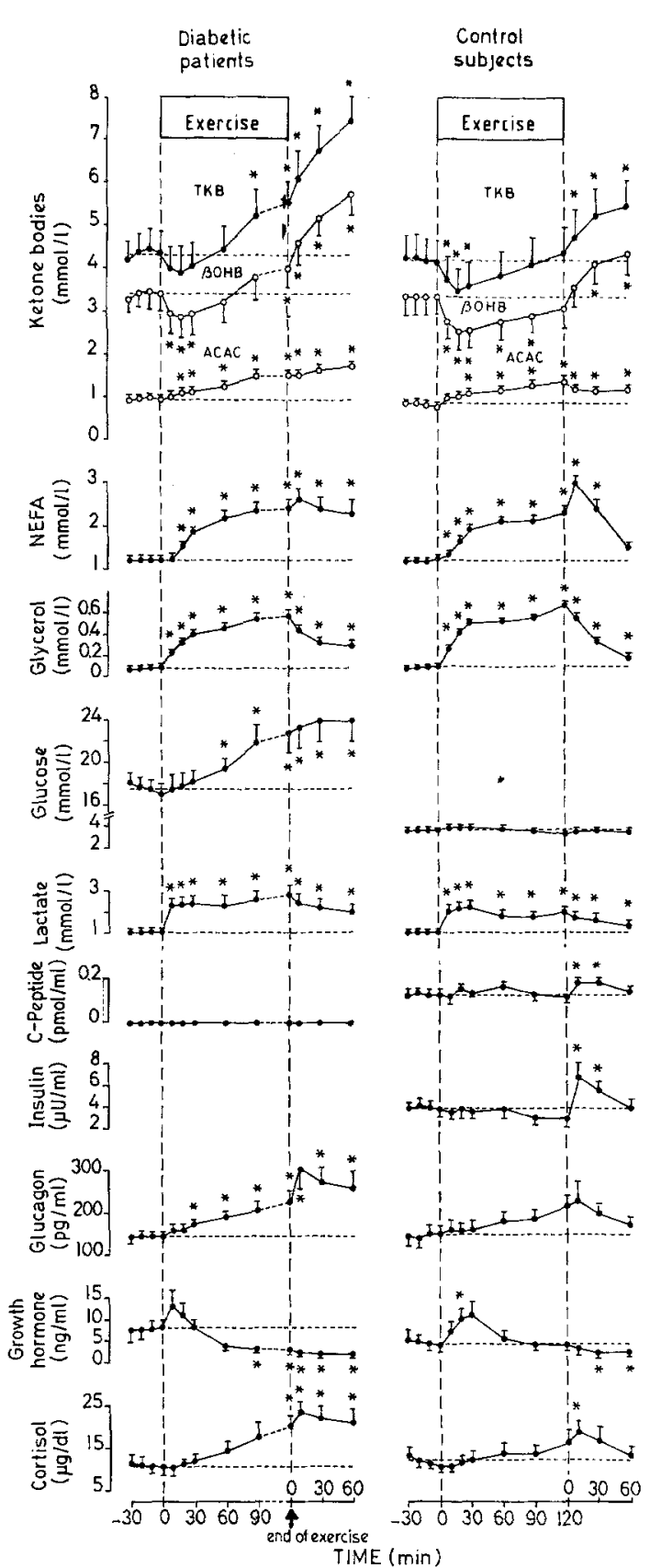

Fig. 1. Substrate and hormone concentrations during and after exercise in 6 ketotic Type 1 diabetic patients and 6 fasted normal subjects presenting a similar degree of ketosis. The mean value at end of exercise was calculated from the data obtained at $120 \mathrm{~min}$ in 4 patients and at $90 \mathrm{~min}$ in 2 patients. Asterisks indicate statistically significant changes from mean basal value $(p<0.05)$. ACAC: acetoacetate; $\beta \mathrm{OHB}: \beta$-hydroxybutyrate; TKB: total ketone bodies; NEFA: nonesterified fatty acids

$0.09 \mathrm{mmol} / 1 \quad(p<0.01)$ at termination of work and $+2.37 \pm 0.18 \mathrm{mmol} / 1(p<0.01)$ after a recovery time of $60 \mathrm{~min}$. Total KB levels paralleled those of $\beta$-hydroxybutyrate, but the changes from mean basal values were statistically significant only during the last $30 \mathrm{~min}$ of work and the postexercise period (Fig.1). The pattern of changes in ketonaemia observed in diabetic patients was qualitatively comparable to that observed in the 


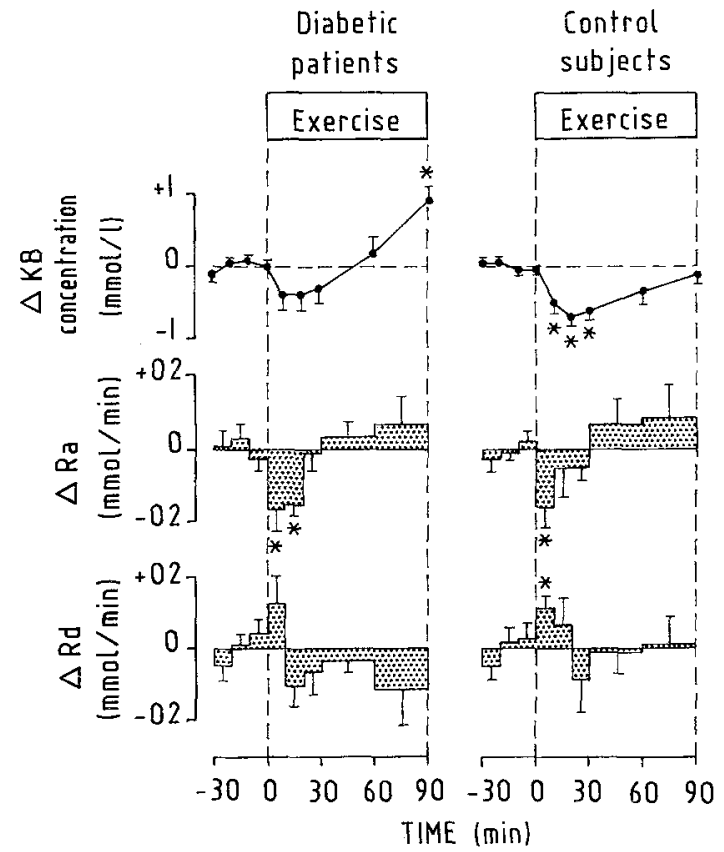

Fig. 2. Changes from mean basal value induced by exercise in the concentration and turnover rate of total ketone bodies $(\mathrm{KB})$ induced by exercise in 6 ketotic Type 1 diabetic patients and 6 normal fasted subjects presenting a similar degree of ketosis (same patients as in Fig. 1). Ra: rate of appearance; Rd: rate of disposal. The kinetic data have been normalized to a body surface of $1.73 \mathrm{~m}^{2}$. Asterisks refer to significant changes from mean basal value $(p<0.05)$

fasted control subjects. However, in the latter group the initial fall in total $\mathrm{KB}$ concentration was more pronounced and statistically significant $(p<0.005)$, whereas the subsequent increase in ketonaemia reached statistical significance $(p<0.01)$ only during the postexercise period (Fig.1). Statistical significance of differences between groups for the exercise-induced changes in $\mathrm{KB}$ concentration was performed for the following time periods: $0-30 \mathrm{~min}, 30-90 \mathrm{~min}$, end of exercise and postexercise. For these successive periods, $p$ values were respectively $>0.05,>0.05,>0.05$ and $<0.001$ for $\Delta$ acetoacetate, $>0.05,<0.02,<0.001$ and $<0.001$ for $\Delta \beta$-hydroxybutyrate and $>0.05,<0.05,<0.001$ and $<0.001$ for $\Delta$ total KB. In the diabetic patients, the $\beta$-hydroxybutyrate/acetoacetate ratio averaged $3.69 \pm 0.13$ at rest, $2.70 \pm 0.21$ at the end of exercise and $3.31 \pm 0.10$ at the end of the postexercise period. Corresponding values in the control subjects were respectively $4.11 \pm 0.40,2.31 \pm 0.04$ and $3.58 \pm 0.34$ and were not statistically different from those of the diabetic patients.

Glucose level increased significantly during and after work in diabetic patients $(+6.33 \pm 1.22 \mathrm{mmol} / 1$ at $180 \mathrm{~min} ; p<0.005$ ), whereas it remained unchanged in control subjects, the difference between the 2 groups being statistically significant $(p<0.001)$ during the whole test from min 30 onwards. The exercise- and postexercise-induced changes in NEFA, glycerol and lactate concentrations did not differ statistically between groups. C-peptide level remained undetectable in diabetic patients during and after exercise and exhibited a slight rebound after cessation of work in the control subjects, paralleling the changes in insulin levels. Glucagon, growth hormone and cortisol levels were similarly affected by work in both groups, but the rise in glucagon was statistically significant $(p<0.05)$ only in the diabetic patients. Comparison between groups for the various hormonal changes showed no statistically significant difference whatever the experimental period considered.

Ketone body kinetics. Figure 2 compares in the same two groups the changes in $\mathrm{Ra}$ and $\mathrm{Rd}$ observed during the initial $90 \mathrm{~min}$ of exercise. This time limit was imposed by the fact that, as mentioned earlier, 2 of the diabetic patients did not exercise longer than $90 \mathrm{~min}$. In both groups, the fall in total KB concentration observed during the initial $20 \mathrm{~min}$ of work was due to the combination of a decrease in $\mathrm{Ra}(\sim-0.2 \mathrm{mmol} / \mathrm{min})$ and an increase in $\mathrm{Rd}(\sim+0.1 \mathrm{mmol} / \mathrm{min})$. These initial changes from baseline value were statistically significant $(p<0.05)$ except for the rise in $\mathrm{Rd}$ in diabetic patients. After this initial period, the secondary rise in total KB levels observed in both groups resulted from a progressive increase in $\mathrm{Ra}$ and a variable fall in $\mathrm{Rd}$, Although $\Delta \mathrm{Ra}$ and $\Delta \mathrm{Rd}$ recorded during the $30-90$ min period were not significantly different between groups, the stimulation of ketogenesis tended to be less marked and the inhibition of Rd more marked in the diabetic group. Urinary loss of total KB averaged $2.4 \pm 0.7 \%$ of total disposal rate in the diabetic patients, versus $2.5 \pm 0.6 \%$ in the fasted control subjects.

The mode of presentation used in Figure 2 has the advantage of showing the temporal evolution of the kinetic changes induced by exercise. However, it has a major drawback. Indeed, the two groups are composed of subjects with quite variable degrees of hyperketonaemia. In agreement with previous observations [8], this causes a great heterogeneity in $\mathrm{KB}$ response to work. Under these conditions, the averaging of the data tends to obscure the differences between normal subjects and diabetic patients. In order to analyze the results on the basis of individual data (Fig.3), we calculated for all diabetic patients and control subjects of Table 1 the integrated changes in Ra and Rd over the initial 90 min of work. These integrated data, as well as the changes in $\mathrm{KB}$ concentration recorded at $90 \mathrm{~min}$, were then correlated to pre-exercise ketonaemia. Figure 3 shows that in the diabetic patients as well as in the control subjects, $\Delta \mathrm{Ra}$ and $\Delta \mathrm{Rd}$ are negatively correlated with basal ketonaemia. For both parameters, the stimulatory effect of work observed at low KB levels is reversed to an inhibitory effect when initial ketonaemia exceeds a critical level of about $4 \mathrm{mmol} / \mathrm{l}$. Covariance analysis indicates that the slopes and elevations of the regression lines characterizing the relationships between $\Delta \mathrm{Ra}$ and $\Delta \mathrm{Rd}$ on one hand and 

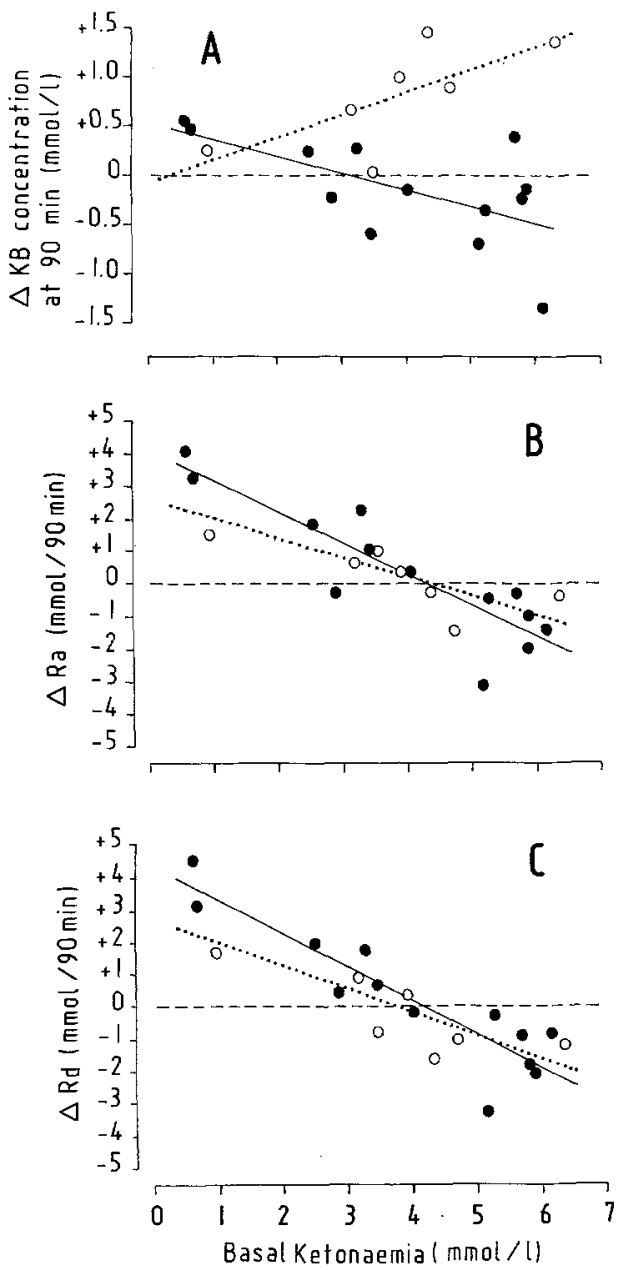

Fig. 3. Panel A: relationship between changes in ketone body concentrations recorded at the 90th min of exercise and basal ketonaemia. Panels $B$ and $C$ : relationships between the integrated changes in the rate of production $(\Delta \mathrm{Ra})$ and the rate of disposal $(\Delta \mathrm{Rd})$ of total ketone bodies (KB) calculated over $90 \mathrm{~min}$ of exercise on one hand, and basal ketonaemia on the other hand. control fasted subjects; $O \ldots O$ Type 1 diabetic patients. Coefficients of correlation and their statistical significance: Panel A: control subjects: $\mathrm{r}=-0.61(p<0.05)$; diabetic patients: $r=+0.71(0.05<p<$ $0.1)$. Panel B: control subjects: $r=-0.87(p<0.001)$; diabetic patients: $r=-0.76(p<0.05)$. Panel $\mathrm{C}$ : control subjects: $r=-0.91$ $(p<0.001)$; diabetic patients: $r=-0.82(p<0.05)$. Covariance analysis indicates that the slopes and elevation of the regression lines are not significantly different for the two groups $(p>0.05)$, except for panel A, where slopes are significantly different $(p<0.01)$

basal ketonaemia on the other hand were not significantly different for diabetic patients as compared to fasting control subjects (Fig. 3). On the other hand, the negative relationship between $\triangle \mathrm{KB}$ concentration and basal ketonaemia observed in control subjects does not apply to diabetic patients in whom $\triangle \mathrm{KB}$ tends to be positively correlated with pre-exercise KB levels, the slopes of the 2 regression lines being significantly different $(p<0.01)$.

In both groups the absence of relationship between exercise-induced $\triangle$ NEFA and $\triangle$ glycerol on one hand, and basal ketonaemia on the other hand (Fig.4), indi-

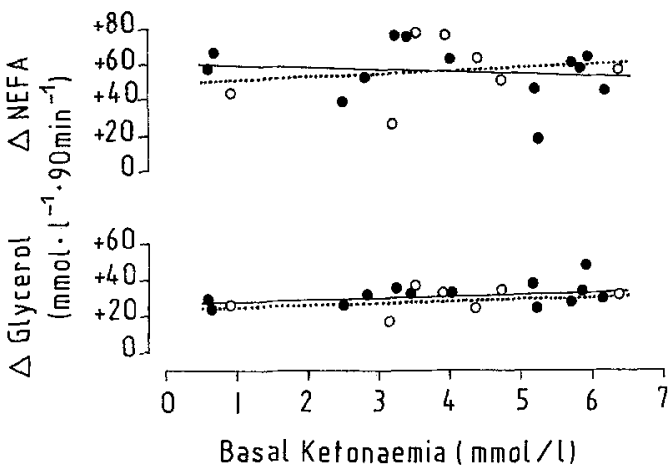

Fig.4. Relationship between the exercise-induced changes in nonesterified fatty acid ( $\triangle$ NEFA) and glycerol ( $\triangle$ glycerol) concentrations on one hand and basal ketonaemia on the other hand. - control fasted subjects; $0 \ldots$ Type 1 diabetic patients. $\triangle N E F A$ and $\triangle$ glycerol represent the integrated incremental concentrations over $90 \mathrm{~min}$ of exercise. Correlation coefficients: $\triangle$ NEFA: control subjects: $r=-0.19$; diabetic patients: $r=+0.31$. $\Delta$ glycerol: control subjects: $r=+0.48$; diabetic patients: $r=+0.46$. None of the correlation coefficients was significantly different from zero at the 0.05 level

cates that the extent to which adipose tissue lipolysis was stimulated by work is independent of the initial $\mathrm{KB}$ level under our experimental conditions.

\section{Discussion}

This study analyzes the response of total $\mathrm{KB}$ turnover to moderate exercise in ketotic diabetic subjects. Six of the seven Type 1 diabetic patients studied (Table 1) had unmeasurable plasma levels of C-peptide; according to the design of the study, it can be anticipated that they were free of any residual subcutaneous insulin depot that could be released during the course of the study. Only the least ketotic patient had some residual insulin secretory capacity, but the C-peptide level was very low despite significant hyperglycaemia, and it did not change during exercise.

In the resting state, when compared at the same ketonaemia, the turnover rate of total $\mathrm{KB}$ are quite similar in diabetic patients and fasted normal control subjects. This confirms our earlier observation made on a much larger sample of normal subjects and diabetic patients [21]. Interestingly, this similarity also applies to the concentration of the other substrates and hormones (Fig. 1), except for glucose and C-peptide.

During exercise, the time course of the changes in $\mathrm{Ra}$ in diabetic patients and control subjects (Fig. 2) is characterized by an initial fall lasting for about $20 \mathrm{~min}$, followed by a secondary rise. As discussed elsewhere [8], this biphasic pattern might be explained by the following mechanisms: the initial decrease in Ra occurs before any significant change in NEFA levels and is probably related to a decrease in the hepatic NEFA load that results from the exercise-induced reduction in splanchnic blood flow [6]. Subsequently, despite the 
persistant inhibition in splanchnic blood flow, $\mathrm{Ra}$ is stimulated by the combined effects of the rise in NEFA concentration and the enhancement of the ketogenic capacity of the liver associated with work [5, 7]. Although this biphasic evolution of $\mathrm{Ra}$ applies to all degrees of hyperketonaemia examined in this study, it should be noted that the higher the initial hyperketonaemia, the less $\mathrm{Ra}$ is stimulated in late exercise, so that the changes in $\mathrm{Ra}$ integrated over the working period are negatively correlated with basal ketonaemia. According to Figure 3 , the $\mathrm{KB}$ concentration at which the overall stimulatory effect of a 90-min exercise on ketogenesis is reversed to an inhibitory action approximates $4 \mathrm{mmol} / 1$ in diabetic patients as well as in normal fasted subjects. The explanation for this negative relationship is not readily apparent. Obviously it cannot be accounted for by differences in NEFA response because the intensity of the lipolytic response to work was unrelated to basal ketonaemia within the range of ketosis investigated in the present study (Fig.4). We would like to hypothesize that this process is largely mediated by the fact that the degree of stimulation of the ketogenic capacity of the liver by exercise probably depends on the initial KB level. It has been shown in the resting state, that the hepatic fractional conversion of NEFA to ketones increases with ketonaemia, amounting to about $40-60 \%$ at $1-2 \mathrm{mmol} / 1[6-7]$ and $80-90 \%$ when ketonaemia exceeds $4 \mathrm{mmol} / 1$ [5, 22]. This fractional conversion is stimulated by work and approaches $100 \%$ in exercising diabetic patients with a ketonaemia of $1 \mathrm{mmol} / 1$ or more [7]. Therefore, the most ketotic diabetic patients are probably unable to augment significantly their intrahepatic conversion of NEFA to ketones during exercise because it is already near maximum at rest. In this perspective, the overall modulation of $\mathrm{Ra}$ by exercise could be viewed as follows: at the exercise intensity used in this study, the splanchnic blood flow is divided by a factor of about 2 [23]. Since the average increase in NEFA concentration during $90 \mathrm{~min}$ of work does not exceed $60 \%$, the overall effect of exercise must have been to significantly reduce NEFA delivery to the liver in all our diabetic patients. This would tend to inhibit ketogenesis at work, but it is variably antagonized by the exercise-induced stimulation of the fractional conversion of NEFA to ketones. On the whole the balance between these two opposite processes favors an enhancement of ketogenesis by exercise at low ketonaemia and its inhibition at high ketosis.

Despite the fact that the negative relationship between the exercise-induced changes in $\mathrm{Ra}$ and basal ketonaemia are similar in normal subjects and diabetic patients (Fig.3), the response of concentration to exercise differs between groups. In the control subjects, concentration is negatively correlated to basal ketonaemia, which suggests that in this group the changes in concentration are mainly influenced by the changes in Ra. On the contrary, in diabetic patients $\Delta$ concentra- tion tends to be positively correlated to basal ketonaemia, suggesting that the hyperketonaemic action of exercise in uncontrolled diabetic patients cannot be accounted for by an exaggerated stimulation of ketogenesis. The hyperketonaemic effect of exercise in ketotic diabetic patients must therefore originate in some defect in the removal mechanisms for ketones, exhibiting in diabetic patients a greater imbalance between production and uptake. This is not inconsistent with the observation that $\mathrm{Rd}$ is depressed at high ketosis in diabetic patients, as it is in normal subjects. Simply, the mechanism responsible for this inhibition is different in the two groups: in fasted subjects, the fall in $\mathrm{Rd}$ can be accounted for by the fall in concentration; in diabetic subjects, $\mathrm{Rd}$ decreases despite a rise in concentration, which implies a reduction in the ability of tissues to take up ketones.

The mechanism of the accelerated development of postexercise hyperketonaemia observed in the diabetic patients cannot be fully discussed because KB turnover data are not available for this period. The finding that in comparison with control subjects, diabetic patients tend to maintain more elevated levels of NEFA, glucagon and cortisol for at least one hour after exercise, suggests that the postexercise recovery period is characterized by a more ketogenic environment in the diabetic patients. This difference should be reinforced by the likely absence in the diabetic patients of the postexercise rebound in insulin concentration seen in the control subjects.

The hyperketonaemic effect of prolonged exercise in ketotic diabetic patients is a well recognized phenomenon [1, 24], and our present results are in complete agreement with this notion. It is generally stated that this abnormal response of diabetic patients results from an exaggerated stimulation of ketogenesis $[4,5,7$, $25,26]$, but in reality there are very few experimental data to support this concept. Wahren et al. [5, 7], using the hepatic catheterization technique, have shown that the increase in $\mathrm{KB}$ production induced by prolonged exercise is exaggerated in the diabetic patients as compared to control overnight fasted subjects, and that the ketogenic response is more pronounced in ketotic than in nonketotic patients. There are at least two reasons why these authors came to conclusions opposite ours with regard to the regulation of ketogenesis in diabetic patients at work. Firstly, it is probable that their patients were less completely deprived of insulin than ours at the time of the study: the shorter delay between the last subcutaneous insulin injection and the experiment, the absence of hyperglycaemic effect of work and the finding that the rise in NEFA was smaller in diabetic patients than in normal control subjects are in favour of this hypothesis. Secondly, they did not compare the pathologic ketosis of diabetes with the physiologic ketosis of fasting at a similar degree of hyperketonaemia. As shown in previous work from our laboratory, this precaution is essential for a correct in- 
terpretation of the effects of exercise on $\mathrm{KB}$ metabolism, the response to work being highly dependent on the initial degree of ketosis [8].

In conclusion, when insulin-deprived, insulin-dependent diabetic patients with a variable degree of hyperketonaemia are submitted to moderate exercise of 120-min duration, their KB metabolism is modified in a manner very similar to that of control fasted subjects matched for ketonaemia. In both groups, at low ketonaemia, exercise stimulates the rate of production and the rate of disposal of ketones. These effects are progressively attenuated as basal ketonaemia rises and are even reversed in markedly ketotic patients. However, ketotic diabetic patients exhibit an abnormal response in increasing their ketonaemia above basal level during the second hour of exercise, a phenomenon not observed in the control subjects. Contrary to the prevailing opinion, this does not seem to result from an exaggerated increase in ketogenesis, but from a slight removal defect possibly related to insulinopenia [27]. It should be emphasized that this conclusion applies to the specific experimental conditions used in this study regarding the duration and intensity of exercise.

Acknowledgements. Thanks are due to M.A. Neef for expert technical assistance and to C. Demesmaeker for secretarial help. This work was supported by the Fonds de la Recherche Scientifique Médicale Belge (grant 3.4541.84), by la Loterie Nationale Belge and by the Fondation Erasme.

\section{References}

1. Vranic M, Berger M (1979) Exercise and diabetes mellitus. Diabetes 28: $147-163$

2. Berger M, Berchtold $P$, Cüppers HJ, Drost $H$, Kley HK, Müller WA, Wiegelmann W, Zimmermann-Telschow H, Gries FA, Krüskemper HL, Zimmermann H (1977) Metabolic and hormonal effects of muscular exercise in juvenile type diabetics. Diabetologia 13: 355-365

3. Berger M, Berchtold P, Kemmer FW (1981) Metabolic and hormonal effects of exercise in diabetic patients. In: Browlee $M(\mathrm{ed})$ Handbook of diabetes mellitus. Intermediary metabolism and its regulation, Vol 3. Garland STPM, New York London, pp 273-305

4. Zinman B, Vranic M (1985) Diabetes and exercise. Med Clin North Am 69: 145-157

5. Wahren J, Hagenfeldt L, Felig P (1975) Splanchnic and leg exchange or glucose, amino acids, and free fatty acids during exercise in diabetic mellitus. J Clin Invest 55: 1303-1314

6. Sestoft L, Trap-Jensen L, Lyngsøe J, Clausen JP, Holst JJ, Nielsen SL, Rehfeld JF, Schaffalitzky De Muckadell O (1977) Regulation of gluconeogenesis and ketogenesis during rest and exercise in diabetic subjects and normal men. Clin Sci Mol Med 53: $411-418$

7. Wahren J, Sato Y, Östman J, Hagenfeldt L, Felig P (1984) Turnover and splanchnic metabolism of free fatty acids and ketones in insulin-dependent diabetics at rest and in response to exercise. J Clin Invest 73: 1367-1376
8. Féry F, Balasse EO (1986) Response of ketone body metabolism to exercise during the transition from the postabsorptive to the fasted state. Am J Physiol 250: E495-E501

9. Ástrand PO, Rhyming I (1954) A nomogram for calculation of aerobic capacity (physical fitness) from pulse rate during submaximal work. J Appl Physiol 7: 218-221

10. Bergmeyer HU (1974) Methods of enzymic analysis, 2nd edn. Academic, New York London

11. Trout DL, Estes EH, Friedberg SJ (1960) Titration of free fatty acids of plasma: a study of current methods and a new modification. J Lipid Res 1: 199-202

12. Virasoro E, Copinschi G, Bruno OD, Leclercq R (1971) Radioimmunoassay of human growth hormone using a charcoal-dextran separation procedure. Clin Chim Acta 31: 294-297

13. Faloona GR, Unger RH (1974) Glucagon. In: Jaffe BM, Behrman HR (eds) Methods of hormone radioimmunoassay. Academic, New York, pp 317-330

14. Mayes PA, Felts JM (1967) Determination of ${ }^{14} \mathrm{C}$-labeled ketone bodies by liquid-scintillation counting. Biochem $\mathrm{J} 102$ : 230-235

15. Balasse EO, Neef MA (1975) Inhibition of ketogenesis by ketone bodies in fasting humans. Metabolism 24: 999-1007

16. Steele R (1959) Influence of glucose loading and of injected insulin on hepatic glucose output. Ann NY Acad Sci 82: 420-430

17. Balasse EO, Féry F, Neef MA (1978) Changes induced by exercise in rates of turnover and oxidation of ketone bodies in fasting man. J Appl Physiol 44: 5-11

18. Féry F, Balasse EO (1983) Ketone body turnover during and after exercise in overnight-fasted and starved humans. Am J Physiol 245: E318-E325

19. Jennrich R, Sampson P, Frane J (1981) Analysis of variance and covariance including repeated measures. In: Dixon WJ (ed) BMDP Statistical software. University of California. Berkeley Los Angeles London, pp 359-387

20. Snedecor GM (1956) Statistical methods, 5th edn. Ames, Iowa: Iowa State University Press

21. Féry F, Balasse EO (1985) Ketone body production and disposal in diabetic ketosis. A comparison with fasting ketosis. Diabetes 34: $326-332$

22. Owen OE, Block BSB, Patel M, Boden G, McDonough M, Kreulen T, Shuman CR, Reichard GA Jr (1977) Human splanchnic metabolism during diabetic ketoacidosis. Metabolism 26: 381-398

23. Smith EE, Guyton AC, Manning RD, White RJ (1976) Integrated mechanisms of cardio-vascular response and control during exercise in the normal human. Prog Cardiovasc Dis 18: 421-443

24. Vignati L, Cunningham LN (1985) Exercise and diabetes. In: Marble A, Krall LP, Bradley A, Christlieb AR, Soeldner JS (eds) Joslin's diabetes mellitus, 12th edn. Lea and Febiger, Philadelphia, pp 453-464

25. Wahren J, Felig P, Hagenfeldt L (1978) Physical exercise and fuel homeostasis in diabetes mellitus. Diabetologia 14: 213-222

26. Wahren J, Hagenfeldt L (1984) Free fatty acid and ketone body utilization under normal and pathophysiological conditions. In: Melchionda N, Horwitz DL, Schade DS (eds) Recent advances in obesity and diabetes research. Raven, New York, pp 353-365

27. Balasse EO, Havel RJ (1971) Evidence for an effect of insulin on the peripheral utilization of ketone bodies in dogs. J Clin Invest 50: $801-813$

Received: 29 September 1986

and in revised form: 5 March 1987

Professor E.O. Balasse

Laboratory of Experimental Medicine

University of Brussels

115, Boulevard de Waterloo

B-1000 Brussels

Belgium 